\title{
Development of a marking nut desheller
}

\author{
A.K. Bhardwaj, S.R. Patil, R.S. Sharma and V.V. Malwade
}

Received : 16.05.2018; Revised : 04.08.2018; Accepted : 21.08 .2018

See end of the Paper for authors' affiliation Correspondence to :

A.K. Bhardwaj Department of Agricultural Engineering, Maharashtra Institute of Technology, Aurangabad (M.S.) India Email : adityabhardwaj128@ gmail.com
-ABSTRACT : Marking nut or 'Semecarpus anacardium L. 'is a versatile tree found abundantly in humid regions of world. Its unique physical trait sets it apart from other agricultural produce; no nut has same shape and size there is a tremendous variation in length, width and thickness of nuts. Nut is a double walled shell and between the cellular space of double walls there is a presence of toxic resin called BSL (Bhilawan shell liquid). Present desheller is simple in its operation and is developed focusing its future potential. It comprises of a double acting pneumatic cylinder (32 bore), solenoid valve, a nut placing die, operative tool and air compressor. Nuts are placed in a specific flat position at centre of cylindrical die, this die is drilled in center so that the stroke passes completely through its centre and is positioned just below the stroke of pneumatic cylinder. A tapered tool screwed with cylinder stroke of $50 \mathrm{~mm}$ and when stroke occurs its cuts through the nuts center and kernel separation is done. It provide 100 per cent protection from splashing of BSL and no human strength for deshelling. Trails were conducted at three different pressures to evaluate performance of machine at $4.8,6.2$ and $7.8 \mathrm{~kg} / \mathrm{cm}^{2}$ and 300 nuts at 2.38 per cent M.C. (dry basis) were cracked at each pressure. Highest efficiency was observed at $6.2 \mathrm{~kg} / \mathrm{cm}^{2}$ and removal of whole kernel was also good. At $6.2 \mathrm{~kg} / \mathrm{cm}^{2}$ pressure 86.20 per cent efficiency and $0.68 \mathrm{~kg} / \mathrm{hr}$ capacity were observed. Machine cost with optimum design is approx. 7500INR.

- KEY WORDS : Marking nut, Double walled shell, Toxic resin, Pneumatic cylinder

-HOW TO CITE THIS PAPER : Bhardwaj, A.K., Patil, S.R., Sharma, R.S. and Malwade, V.V. (2018). Development of a marking nut desheller. Internat. J. Agric. Engg., 11(2) : 289-293, DOI: 10.15740/ HAS/IJAE/11.2/289-293. Copyright@2018: Hind Agri-Horticultural Society. 